\title{
Comparison of piezosurgery and traditional saw in bimaxillary orthognathic surgery
}

\author{
Giuseppe Spinelli ${ }^{\mathrm{a}}$, Davide Lazzeri ${ }^{\mathrm{b}}$, Marco Conti ${ }^{\mathrm{a}}$, Tommaso Agostini ${ }^{\mathrm{a}}$, \\ Giuditta Mannelli ${ }^{\mathrm{c}, *}$ \\ ${ }^{a}$ Traumatology and Maxillo-Facial Surgery Unit (Head in Chief Dr. Giuseppe Spinelli), Orthopedic Traumatological Center, Azienda Ospedaliera \\ Universitaria Careggi, Florence, Italy \\ ${ }^{\mathrm{b}}$ Plastic and Reconstructive Surgery Unit, Hospital of Pisa, Italy \\ ${ }^{c}$ First Clinic of Otolaryngology, Department of Surgery and Translational Medicine, University of Florence, Via Largo Brambilla 3 , \\ 50134 Florence, Italy
}

\section{A R T I C L E I $\mathrm{N}$ F O}

\section{Article history:}

Paper received 30 July 2013

Accepted 18 February 2014

\section{Keywords:}

Piezoosteotomy

Orthognathic surgery

Jaw and maxillary osteotomies

Blood loss

Nerve impairment

\begin{abstract}
A B S T R A C T
Purpose: Investigators have hypothesised that piezoelectric surgical device could permanently replace traditional saws in conventional orthognathic surgery.

Methods: Twelve consecutive patients who underwent bimaxillary procedures were involved in the study. In six patients the right maxillary and mandible osteotomies were performed using traditional saw, whilst the left osteotomies by piezoosteotomy; in the remaining six patients, the surgical procedures were reversed. Intraoperative blood loss, procedure duration time, incision precision, postoperative swelling and haematoma, and nerve impairment were evaluated to compare the outcomes and costs of these two procedures.

Results: Compare to traditional mechanical surgery, piezoosteotomy showed a significant intraoperative blood loss reduction of $25 \%$ ( $p=0.0367$ ), but the mean surgical procedure duration was longer by $35 \%$ $(p=0.0018)$. Moreover, the use of piezoosteotomy for mandible procedure required more time than for the maxillary surgery $(p=0.0003)$. There was a lower incidence of postoperative haematoma and swelling following piezoosteotomy, and a statistically significant reduction in postoperative nerve impairment $(p=0.003)$.

Conclusions: We believe that piezoelectric device allows surgeons to achieve better results compared to a traditional surgical saw, especially in terms of intraoperative blood loss, postoperative swelling and nerve impairment. This device represents a less aggressive and safer method to perform invasive surgical procedures such as a Le Fort I osteotomy. However, we recommend the use of traditional saw in mandible surgery because it provides more foreseeable outcomes and well-controlled osteotomy. Further studies are needed to analyse whether piezoosteotomy could prevent relapse and promote bony union in larger advancements.
\end{abstract}

(C) 2014 European Association for Cranio-Maxillo-Facial Surgery. Published by Elsevier Ltd. All rights reserved.

\section{Introduction}

Traditional ultrasonic surgery has been used in dental practice since the 1940s (Lynn et al., 1942). In the following decades, it has been applied to the following more challenging oral surgical procedures: alveolar ridge expansion (Blus and Szmukler-Moncler, 2006; Schlee et al., 2006) exposure of impacted canines (Grenga

\footnotetext{
* Corresponding author. Tel.: +39 0557947988; fax: +39 055435649.

E-mail address: mannelli.giuditta@gmail.com (G. Mannelli).
}

and Bovi, 2004), lateralisation of the inferior alveolar nerve (Bovi, 2005), sinus lifts for the placement of implants (Eggers et al., 2004; Stübinger et al., 2005; Barone et al., 2008), endodontic and periodontal surgery (Vercellotti and Pollack, 2006; Peñarrocha et al., 2007), and to harvest autologous bone grafts (Sohn et al., 2007). The end of the second millennium saw the growing clinical introduction of the ultrasonic scalpel (Shelley and Shelley, 1986; Lee and Park, 1999; Gonzalez-Garcia et al., 2009), and it has become competitive with conventional instruments in maxillo-facial surgery for orthognathic operations in certain frameworks (Stübinger et al., 2005; Kotrikova et al., 2006; Landes et al., 
2008a, 2008b; Beziat et al., 2009; Gilles et al., 2013; Hoffmann et al., 2013).

Piezoelectric device involves the use of $60-200 \mu \mathrm{m} / \mathrm{s}$ ultrasonic microvibrations at $24-29 \mathrm{kHz}$ to cut mineralised tissue, allowing soft tissue to remain unharmed at this frequency. This instrument seems to offer several main advantages in oral and maxillo-facial surgery (Stübinger et al., 2005; Kotrikova et al., 2006; Beziat et al., 2007; Landes et al., 2008a, 2008b; Maurer et al., 2008; Beziat et al., 2009; Gonzalez-Garcia et al., 2009; Gilles et al., 2013) such as: (1) minimal risk for soft tissue, which vibrates without fracture when in contact with the osteotome tip; (2) excellent visibility within the surgical field due to minimal bleeding and the cavitation effect removing osteotomic detritus; (3) precision and geometric cutting, due to the limited vibration amplitude and specific design of the osteotome; and (4) low acoustic and vibration impact. However, three main disadvantages have been reported: (1) dense bone cutting could take up to 4 times longer than a traditional rotary saw; (2) it is necessary to maintain a stock of tips; and (3) higher cost than mechanical osteotomes.

All of these characteristics have translated by authors into clinical and surgical results such as a reduction of intraoperative blood loss, more cutting precision, a longer operation duration mean time, a less incidence of postoperative swelling and haematoma, a lower incidence of nerve damage and a faster nerve recovery when impaired (Eggers et al., 2004; Beziat et al., 2007; Landes et al., 2008a, 2008b; Gonzalez-Garcia et al., 2009; PineiroAguillar et al., 2011; Gilles et al., 2013).

In accordance with these findings, here we proposed a prospective clinical study between piezoelectric surgical device and traditional saw use in orthognathic surgery in order to assess whether piezoelectric device could permanently replace the traditional technique in this type of surgical procedure. We performed a comparative analysis between intraoperative and postoperative outcomes of both devices in twelve consecutive patients who underwent bimaxillary procedures for maxillo-facial disorders.

\section{Material and methods}

\subsection{Patients}

Twelve patients who were scheduled to undergo orthognathic surgery, were prospectively enrolled in this study between December 2011 and December 2012 with the assent of the Florence University Hospital IRB. All the participants signed an informed consent agreement. The indications for surgery included the presence of facial skeletal dysmorphia in all 12 patients and sleep apnea symptoms claimed by a single patient. A history of previous orthognathic surgery, maxillo-facial trauma or reconstructive facial surgery, were considered exclusion criteria.

\subsection{Surgical method}

The senior surgeon (G.S.) performed 12 bimaxillary procedures while patients were under general anaesthesia with nasal intubation. The surgical technique was chosen on the basis of the personal experience of the surgeon, by comparing surgical techniques reported in literature (Kahnberg, 1997; Landes et al., 2008a, 2008b; Nada et al., 2010; Gilles et al., 2013). The surgeon prepared and dissected the subperiosteum as usual before performing the bilateral sagittal split osteotomy (BSSO), and the mandibular osteotomy was initiated at $45^{\circ}$ on the lingual ramus side. He penetrated into the cortical bone by going with the tip of the surgical instrument towards the inferior alveolar nerve channel without harming it. The split manoeuvre was performed with a manual rotation after have completed the inferior vertical osteotomy. The preparation of the periosteum for the Le Fort I osteotomy was carried on in the usual fashion through sulcular incisions; both, piezosurgery tip and traditional saw's blade, were pulled around the maxillary tuberosity under video-endoscopic-assisted control and inserted deeper paying attention to not produce haemorrhage. The surgeon then, brought the tip of both instruments towards the anterior sinus wall and then we penetrated the lateral nasal wall over the entire length of the nasal septum, to obtain the final maxillary down-fracture. In this setting, to compare piezoosteotomy characteristics with a traditional mechanical device, the surgeon performed a total of 48 single osteotomies, 24 maxillary and 24 mandible osteotomies, for a total of 4 osteotomies per patient. In six patients out of the twelve the right maxillary and mandible osteotomies were performed using the piezoelectric device, whilst the left osteotomies where performed using a traditional saw. In the remaining six patients the surgical procedures were reversed, and the patients underwent right maxillary and mandible osteotomies using a traditional saw, whilst the left osteotomies were performed using piezoelectric device. The scalpel's ultrasonic osteotome operated at a nominal, non-modulated frequency of $22.5 \mathrm{kHz}$, and the amplitude of the vibrations ranged from 35 to $300 \mathrm{~mm}$.

\subsection{Parameters assessment}

To compare each device's characteristics, we analysed several surgical and clinical parameters on the basis of literature reports (Eggers et al., 2004; Beziat et al., 2007; Landes et al., 2008a, 2008b; Gilles et al., 2013). We analysed the following intraoperative and postoperative parameters:

(1) intraoperative blood loss was evaluated in $\mathrm{mL}$ collected by the same type of calibrated suction instrument during each surgical procedure. A standard amount of $0.9 \%$ saline solution was used to cool the bone and clean the surgical site, and it was counted and subtracted by the total amount of surgical fluids suctioned. This procedure was performed per each side and per each surgical device respectively.

(2) the operative time of the whole surgical procedure was evaluated objectively using OPERA software, an application for computer which helped us in recording the operative time of all of the surgical steps per each side and device, counting positioning, osteotomy and osteosynthesis time, objectively;

(3) incision surgical precision was evaluated subjectively by surgeon's comfort in splitting bone, in terms of force to apply during the osteotomy, attention to pay in order to obtain as much linear resected margins as possible with minimal bone consumption, by comparing the handiness of each device for both maxillary and mandible osteotomy;

(4) postoperative swelling was evaluated using a quantitative method. We took several photos to each patient's frontal, lateral and third-fourth side, in order to document the improvement and evolution of their facial appearance during the postoperative period. By looking at their frontal side picture, we presumed to draw an imaginary line dividing their face vertically along its middle point and horizontally at the level of the chin (Fig. 1). At this point, we measured the difference in millimetres of the extension of the swelling along the horizontal imaginary line using a meter, verifying the presence or absence of haematoma; we performed this analysis at one day, one week, one month, three months and six months after surgery, to compare our results;

(5) nerve impairment was calculated based on a total of 24 mandibular osteotomies using a clinical neurosensory test 


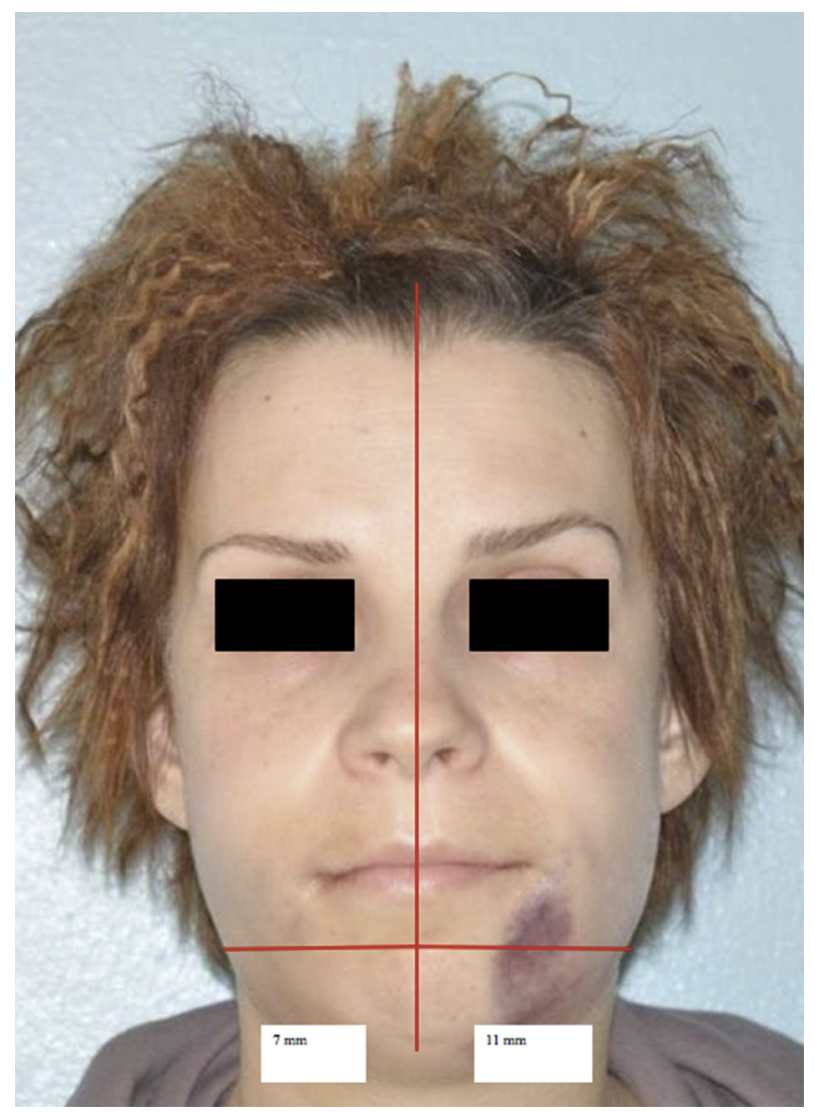

Fig. 1. Quantitative method to measure postoperative swelling: red lines divide face vertically into two equal halves and horizontally at the level of the chin. A meter helps in measuring the swelling's extension in millimetres. Here, the left side is swollen $4 \mathrm{~mm}$ more than the right side, and there is a haematoma.

that was performed on all of the patients preoperatively, on days 1 and 7 postoperatively, and 1, 3 and 6 months after surgery. The same person (G.M.) performed all of the tests, which were carried out in a calm room with the patient relaxed, eyelids closed, in a semi-sitting position, after explaining and performing the test on the hand (free from any sensory disturbance). Reference points were determined over the inferior lip and chin. The right and left sides were examined separately. Patients were asked to evaluate sensory recovery, and the grade of response are shown in Table 1 (Beziat et al., 2007).

Outpatient follow-up included clinical examination on days 1 and 7 after surgery and at 1, 3 and 6 months after surgery. A control $\mathrm{X}$-ray was obtained preoperatively and at 2 days and 1 and 6 months postoperatively in accordance with recommendations made by the IRB. Photographs were taken of the patients after obtaining their informed consent to compare their appearance before and after surgery.

Table 1

Grade of response in nerve sensitivity evaluation on each side during subjective examination.

\begin{tabular}{ll}
\hline Grade & Response \\
\hline 1 & Absent sensation, anaesthesia \\
2 & Severely altered sensation, paraesthesias \\
3 & Moderately altered or slightly reduced sensation \\
4 & Mildly reduced or subnormal sensation \\
5 & Normal sensation \\
\hline
\end{tabular}

\subsection{Statistical analysis}

Mean \pm SD and median were calculated for data variables. Statistical analyses were performed using STATA (Stata Corporation, College Station, TX, USA). A value of $p<0.05$ was considered to be significant.

\section{Results}

Twelve patients affected by dentofacial deformities underwent maxillary surgery. There were 5 men $(42 \%)$ and 7 women (58\%) with a median age at the time of surgery of 25.5 years (mean $26.08 \pm$ SD 5.65, range 18-35 years). Of the 12 patients, 33\% were mild smokers (less than 10 cigarettes per day). Clinical characteristics of patients are summarized in Table 2.

Several intraoperative and postoperative parameters were evaluated for each surgical procedure.

\subsection{Intraoperative parameters}

The intraoperative parameters included estimation of blood loss during surgery $(\mathrm{mL})$ and evaluation of surgical duration time (minutes) (Table 3). Traditional saw presented a minimum blood loss value of $190 \mathrm{~mL}$ and a maximum value of $510 \mathrm{~mL}$; in contrast the ultrasonic device minimum and maximum values of $80 \mathrm{~mL}$ and $350 \mathrm{~mL}$, respectively. The mean blood loss value during the traditional saw procedure was $311.67 \mathrm{~mL} \pm \mathrm{SD} 97.03$ (CI 250.02-373.32), while ultrasonic device use led to blood loss of $237.50 \mathrm{~mL} \pm \mathrm{SD}$ 86.076 (CI 183.060-292.440), which was statistically significant of $p=0.0367$. In contrast, the procedure duration time showed a mean value of $105.25 \mathrm{~min} \pm \mathrm{SD} 36.86$ (CI 81.83-128.67) for traditional saw, whilst piezoosteotomy presented a longer mean procedure time of $163.58 \mathrm{~min} \pm \mathrm{SD} 41.20$ (CI 137.41-189.76), which was also statistically significant $(p=0.0018)$. The minimum and maximum values for saw surgical procedure were 40 and $162 \mathrm{~min}$, respectively, compared with piezoosteotomy's values of 90 and 214 min.

To study in depth the piezoosteotomy properties, the two previous intraoperative parameters were evaluated at different anatomical sites: maxilla and jaw (Table 4). The maxillary procedures presented a minimum value of blood loss of $33.1 \mathrm{~mL}$ and a maximum value of $145 \mathrm{~mL}$; the mandible procedure presented minimum and maximum values of $46.9 \mathrm{~mL}$ and $205 \mathrm{~mL}$, respectively. Maxillary surgery showed a slightly lower mean blood loss (98.308 $\mathrm{mL} \pm$ SD 35.584; CI 75.699-120.917) than mandible surgery (139.400 mL \pm SD 50.514; CI 107.305-171.495), but the

Table 2

Clinical characteristics of the twelve patients.

\begin{tabular}{|c|c|c|c|c|}
\hline Case & $\begin{array}{l}\text { Age } \\
\text { (year) }\end{array}$ & Gender & Smoke & Facial skeletal abnormality \\
\hline 1 & 23 & M & Yes & $\begin{array}{l}\text { Class III dentofacial deformity and } \\
\text { right jaw asymmetry }\end{array}$ \\
\hline 2 & 19 & $\mathrm{~F}$ & No & Class III dentofacial deformity \\
\hline 3 & 28 & $\mathrm{~F}$ & No & Class III dentofacial deformity \\
\hline 4 & 32 & M & Yes & $\begin{array}{l}\text { Class III dentofacial deformity and } \\
\text { partial edentulism }\end{array}$ \\
\hline 5 & 35 & $\mathrm{~F}$ & Yes & Class III dentofacial deformity \\
\hline 6 & 21 & $\mathrm{~F}$ & No & Class III dentofacial deformity \\
\hline 7 & 25 & $\mathrm{~F}$ & Yes & Class III dentofacial deformity \\
\hline 8 & 18 & M & No & $\begin{array}{l}\text { Class III dentofacial deformity and } \\
\text { left jaw asymmetry }\end{array}$ \\
\hline 9 & 34 & M & No & Class III dentofacial deformity \\
\hline 10 & 23 & $\mathrm{~F}$ & No & Class III dentofacial deformity \\
\hline 11 & 26 & M & No & Sever obstructive sleep apnea symptoms \\
\hline 12 & 29 & $\mathrm{~F}$ & No & Class III dentofacial deformity \\
\hline
\end{tabular}


Table 3

Values of intraoperative blood loss and procedure duration times per patient and single device, traditional saw and piezosurgery.

\begin{tabular}{|c|c|c|c|c|}
\hline \multirow[t]{2}{*}{ Case } & \multicolumn{2}{|c|}{ Blood loss (mL) } & \multicolumn{2}{|c|}{ Procedure duration time (minutes) } \\
\hline & Saw & Piezosurgery & Saw & Piezosurgery \\
\hline 1 & 510 & 293 & 110 & 155 \\
\hline 2 & 280 & 80 & 68 & 202 \\
\hline 3 & 392 & 198 & 118 & 180 \\
\hline 4 & 278 & 286 & 131 & 158 \\
\hline 5 & 390 & 261 & 162 & 187 \\
\hline 6 & 265 & 337 & 40 & 214 \\
\hline 7 & 225 & 225.5 & 90 & 120 \\
\hline 8 & 190 & 125 & 128 & 105 \\
\hline 9 & 370 & 145 & 100 & 190 \\
\hline 10 & 210 & 242 & 110 & 210 \\
\hline 11 & 240 & 310 & 56 & 90 \\
\hline 12 & 390 & 350 & 150 & 152 \\
\hline
\end{tabular}

difference was not significant $(p=0.059)$. In contrast, a shorter mean operative duration was found in case of maxillary surgery (range, $40 \mathrm{~min}-82 \mathrm{~min}$ ) with a mean value of $60.58 \mathrm{~min} \pm 15.29$ (CI 50.87-70.30) instead of mandible procedures (range $65 \mathrm{~min}$, $150 \mathrm{~min}$ ) with a mean value of $103.00 \mathrm{~min} \pm 29.00$ (CI 84.58$121.42)$. This difference was statistically significant $(p=0.0003)$.

The ultrasonic device presented a better incision surgical precision outcome compared to the traditional saw, even if this was not scientifically demonstrated. Moreover, piezoosteotomy showed a better cutting precision in cases of maxillary osteotomy compared with mandible osteotomy.

\subsection{Postoperative parameters}

Evaluations of postoperative parameters which were collected during clinical follow-up, were reported for each single device: traditional saw (Table 5) and piezoosteotomy (Table 6). Surgical procedures performed using a traditional saw caused postoperative swelling at 1 week after surgery in 8 of 12 patients (66.6\%) of which 4 recovered within a month while the other 4 patients $(33.3 \%)$ still presented with facial swelling at 1 month after surgery; $16.6 \%$ still had a facial lump 90 days after surgery, and all of the patients recovered within the first 6 postoperative months. Four of the 12 patients had facial haematomas during the first day after surgery; 2 patients healed within the first postoperative week, whilst only one patient still presented with signs of previous haematoma at 1 month after surgery (Fig. 2). Nerve impairment was evaluated as previously mentioned on a total of 24 osteotomies performed using a traditional saw. Approximately $33 \%$ of the analysed sites on the

\section{Table 4}

Intraoperative parameters in piezosurgery evaluated per each patient upon two different anatomical sites: maxilla and jaw.

\begin{tabular}{lccllr}
\hline Case & \multicolumn{2}{l}{ Blood loss $(\mathrm{mL})$} & & \multicolumn{2}{l}{$\begin{array}{l}\text { Procedure duration } \\
\text { time (minutes) }\end{array}$} \\
\cline { 2 - 3 } \cline { 5 - 6 } & Maxilla & Jaw & & Maxilla & Jaw \\
\hline 1 & 121 & 172 & & 55 & 100 \\
2 & 33.1 & 46.9 & 82 & 120 \\
3 & 82.1 & 115.9 & 80 & 100 \\
4 & 118.3 & 167.7 & 60 & 98 \\
5 & 108 & 153 & 77 & 110 \\
6 & 139 & 198 & 64 & 150 \\
7 & 93.3 & 132.2 & 40 & 80 \\
8 & 51.7 & 73.3 & 40 & 125 \\
9 & 59.9 & 85.1 & 65 & 140 \\
10 & 100.1 & 141.9 & 70 & 50 \\
11 & 128.2 & 181.8 & 40 & 98 \\
12 & 145 & 205 & 54 & \\
\hline
\end{tabular}

Table 5

Postoperative parameters evaluated in cases of traditional saw procedures. Each column reports the number of patients affected and their percentage in brackets.

\begin{tabular}{llllll}
\hline Traditional saw & I day & 1 week & 1 month & 3 months & 6 months \\
\hline $\begin{array}{l}\text { Postoperative } \\
\quad \text { swelling }\end{array}$ & $12(100 \%)$ & $8(66.6 \%)$ & $4(33.3 \%)$ & $2(16.6 \%)$ & 0 \\
$\begin{array}{l}\text { Postoperative } \\
\quad \text { haematoma }\end{array}$ & $4(33.3 \%)$ & $2(16.6 \%)$ & $1(8.3 \%)$ & 0 & 0 \\
$\begin{array}{l}\text { Nerve impairment } \\
\text { Normal }\end{array}$ & $2(8 \%)$ & $2(8 \%)$ & $9(38 \%)$ & $14(58 \%)$ & $17(72 \%)$ \\
Mild reduced & $3(13 \%)$ & $3(12 \%)$ & $3(12 \%)$ & $4(18 \%)$ & $4(18 \%)$ \\
Moderately reduced & $9(38 \%)$ & $8(33 \%)$ & $7(29 \%)$ & $3(13 \%)$ & $2(8 \%)$ \\
Severely reduced & $2(8 \%)$ & $4(16 \%)$ & $2(8 \%)$ & $2(8 \%)$ & $1(3 \%)$ \\
Absent & $8(33 \%)$ & $7(29 \%)$ & $3(13 \%)$ & $1(3 \%)$ & $1(3 \%)$ \\
\hline
\end{tabular}

first day of follow-up after surgery had absent neurosensitivity, but nearly $72 \%$ of patients recovered within the first 6 months.

Piezoosteotomy caused postoperative swelling at 1 week after surgery in 8 of 12 patients (66.6\%): of these patients 6 recovered within a week, while the remaining 2 patients (16.6\%) recovered within the first postoperative month. Postoperative haematoma was observed in a single patient (8.3\%) who healed by the first week. Nerve impairment testing showed that $18 \%$ of the analysed sites presented an absent neurosensitivity on the first day after surgery, and this measurement decreased to $8 \%$ within the first week; a complete recovery of nearly $97 \%$ at 6 months after surgery was observed.

All together these values demonstrated an early statistically significant increased incidence of postoperative swelling following traditional saw procedures compared with ultrasonic surgery $(p=0.05)$ (Fig. 3). There was no significant difference in the incidence of haematoma between the two surgical devices $(p=0.2)$. Nerve impairment analysis did not show any statistically significant different at 1 week after surgery $(p=0.6816)$ (Fig. 4), but after 1 postoperative month of follow-up, the $p$ value reached the significant value of 0.003 . Osteotomies using a saw reported a normal nerve testing at $38 \%$ of sites compared with normal testing at $72 \%$ of site following piezoosteotomy use. Moreover, piezoosteotomy procedures did not present any absent neurosensitivity, which was present in approximately $13 \%$ of site following traditional saw osteotomies (Fig. 5). In our series, improvements of mid-facial deficiencies, as well as improvements in occlusal relationships were obtained (Fig. 6).

\section{Discussion}

Piezoelectric device is a useful surgical device that permits wellcontrolled procedures and precision in bone cutting. The primary advantage of ultrasonic osteotomy, mentioned repeatedly by numerous authors, is the low associated risk to damage adjacent soft tissues, notably the IAN, the periosteum, the schneiderian

Table 6

Postoperative parameters evaluated in cases of piezosurgery procedures. Each column reports the number of patients affected and their percentage in brackets.

\begin{tabular}{llllll}
\hline Piezosurgery & I day & 1 week & 1 month & 3 months & 6 months \\
\hline $\begin{array}{l}\text { Postoperative } \\
\quad \text { swelling }\end{array}$ & $8(66.6 \%)$ & $2(16.6 \%)$ & 0 & 0 & 0 \\
$\begin{array}{l}\text { Postoperative } \\
\quad \text { haematoma }\end{array}$ & $1(8.3 \%)$ & 0 & 0 & 0 & 0 \\
$\quad$ & & & & \\
Nerve impairment & & & & & \\
Normal & $3(15 \%)$ & $7(28 \%)$ & $17(75 \%)$ & $20(84 \%)$ & $23(97 \%)$ \\
Mild reduced & $7(28 \%)$ & $7(28 \%)$ & $4(18 \%)$ & $3(12 \%)$ & $1(3 \%)$ \\
Moderately reduced & $7(28 \%)$ & $4(18 \%)$ & $2(8 \%)$ & $1(3 \%)$ & $0 \%$ \\
Severely reduced & $3(12 \%)$ & $4(18 \%)$ & $1(3 \%)$ & $0 \%$ & $0 \%$ \\
Absent & $4(18 \%)$ & $2(8 \%)$ & $0 \%$ & $0 \%$ & $0 \%$ \\
\hline
\end{tabular}




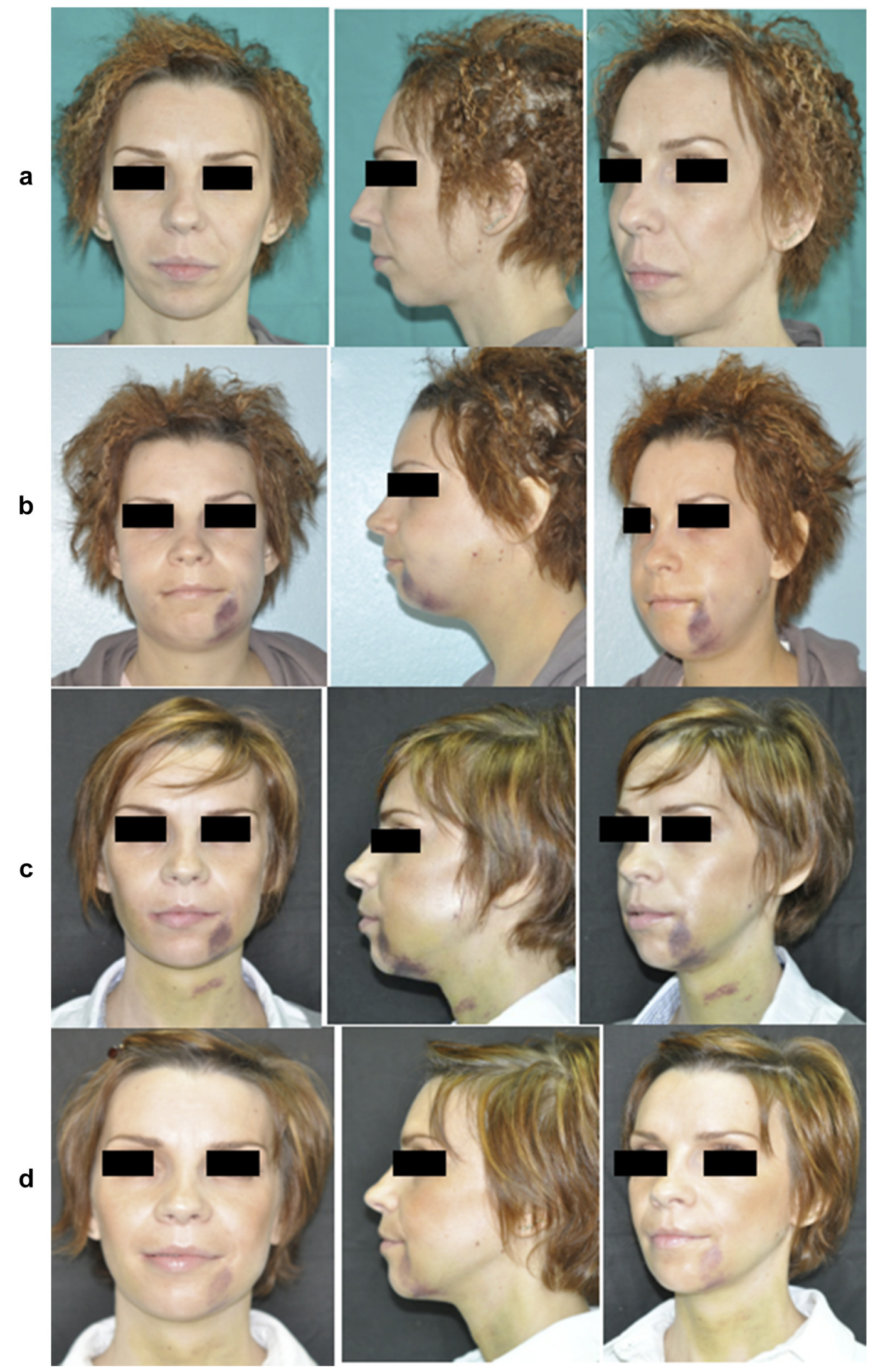

Fig. 2. Postoperative swelling and haematoma evaluation after left traditional saw surgical procedure: a. preoperative appearance; b. 1 day after surgery; c. 1 week after surgery; d. 1 month after surgery. 
30

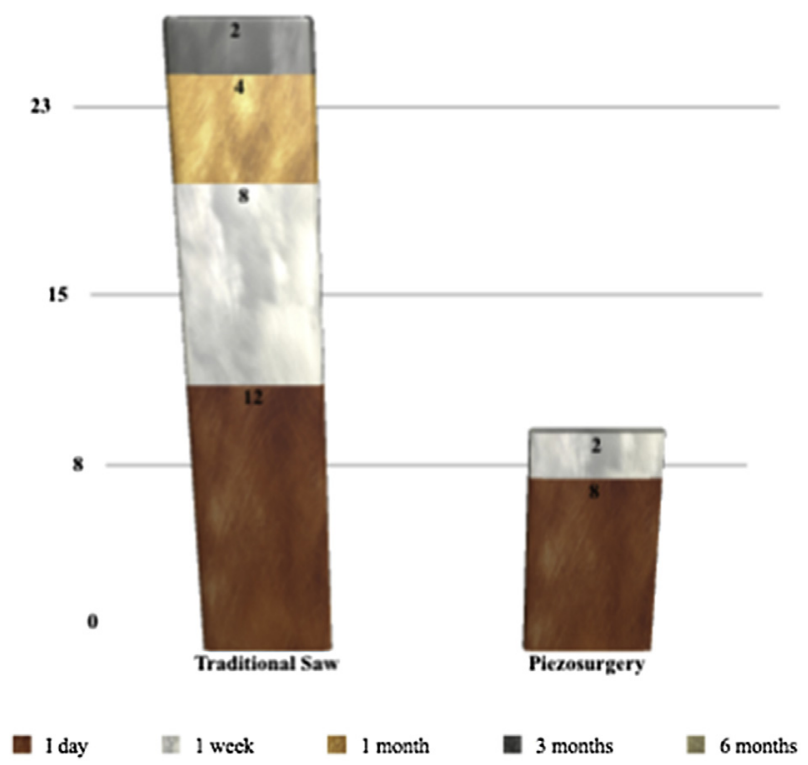

Fig. 3. The graphic shows the incidence of postoperative swelling in traditional saw and piezosurgery procedures $(p=0.05)$. The legend reports each follow-up time associated with a specific colour: brown is for 1 day after surgery, white is for 1 week after surgery, yellow is for 1 month after surgery, dark grey is for 3 months after surgery, light grey is for 6 months after surgery. Each column reports the number of patients who experienced postoperative swelling for each follow-up time.

membrane, and oral mucosa (Nusrath and Postlethwaite, 2011), together with a reduction in blood loss, swelling and nerve impairment (Eggers et al., 2004; Landes et al., 2008a; Gilles et al., 2013); moreover, comparative studies regarding its safety and efficacy in bone surgery (Maurer et al., 2008), proposed it as a possible substitute for traditional saws in orthognathic surgical procedures.

We reported here a comparative study between piezoelectric device and traditional mechanical saw to obtain a scientific report on the consequent outcome quality in orthognathic surgery, in terms of advantages and disadvantages of this technique.

It is well known, that the main disadvantage of ultrasonic osteotomy is its slow cutting rate (Khambay and Walmsley, 2000a, 2000b; Eggers et al., 2004; Kotrikova et al., 2006; Leclercq et al., 2008); although cutting time tends to decrease as the operator gains experience, it is up to 3 or 4 times longer than conventional technique and this is due to the need to allow cooling especially in the case of dense cortical bone cutting (Vercellotti et al., 2001; Eggers et al., 2004; Kramer et al., 2006).

In our series we found that the mean procedure duration time by piezoosteotomy increased $35 \%$ compared with mechanical surgery $(p=0.0018)$.

There are several reports about complications which can occur during orthognathic surgery, where the rate of complications in conventional technique is around $6.4 \%$, with a $1.2-3 \%$ of cases of haemorrhages (Kramer et al., 2004; Telzrow et al., 2005; Landes et al., 2008a, 2008b). In contrast, fewer complications have been reported with piezoelectric devices (Landes et al., 2008a, 2008b), where haemorrhage seems to be about avoided. It is well documented that the blood loss during orthognathic surgery can be considerable; Pineiro-Aguillar and colleagues (Pineiro-Aguillar et al., 2011) reported in their review a mean volume of intraoperative bleeding of $436.11 \mathrm{~mL}$; this massive bleeding is caused by large vessels such as sphenopalatine artery, descending palatine artery, the pterygoid plexus, and the internal maxillary artery with its collateral branches during Le Fort I osteotomies; whilst, in the case of the mandible, the bleeding occurs from the alveolar arteries and the facial artery or branches of these. Thus, bimaxillary surgery results in a major volume of blood loss directly related to the surgical technique, operating time influenced by the device used and the magnitude of the intervention (Yu et al., 2000).

Moreover, it seems to be established a direct proportional relationship between the duration of the intervention and the bleeding volume but in contrast we showed, through our analysis, a significant reduction in mean blood loss of $25 \%$ compared to a traditional saw procedure ( $p=0.0367)$; without any significant difference in blood loss between value upon the two anatomical sites, maxillary and mandible, in piezoelectric surgery against conventional saw technique $(p=0.059)$. In our series there was no significant difference in blood loss between value upon the two

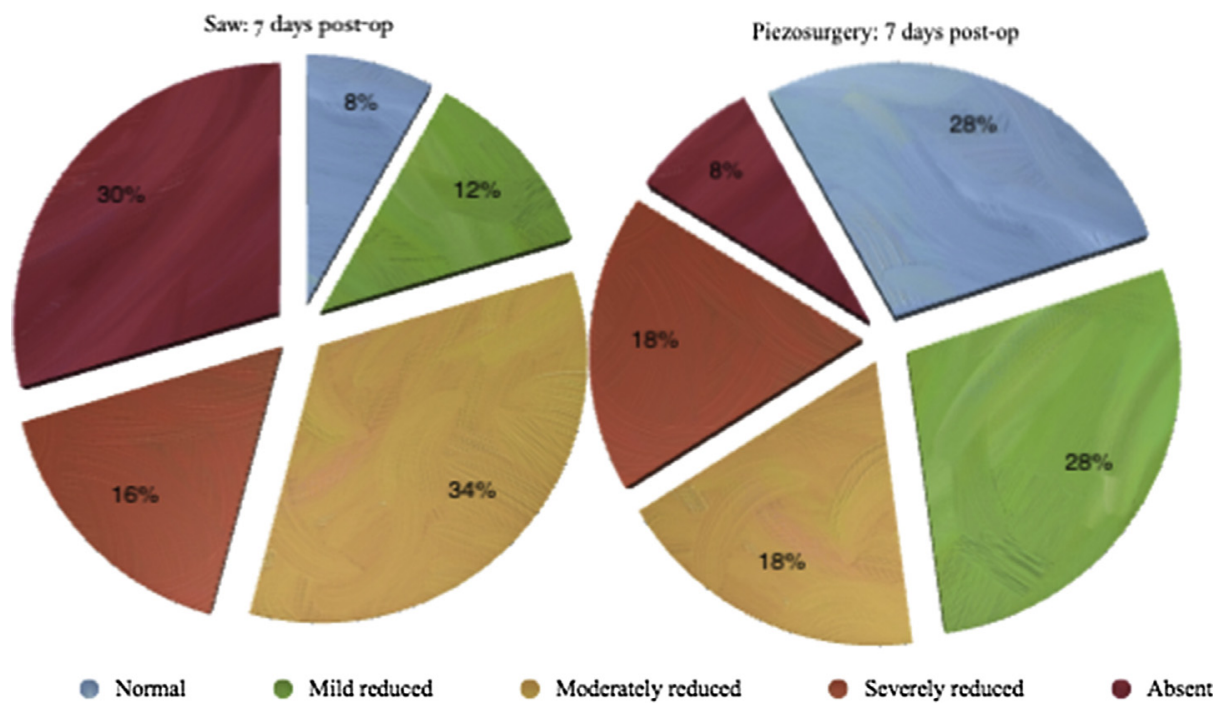

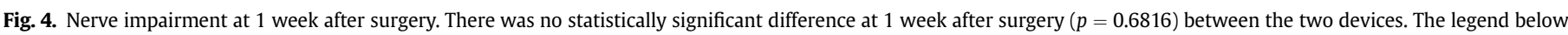
explains each follow-up period, and the numbers reported on the graphic represent each surgical site. 

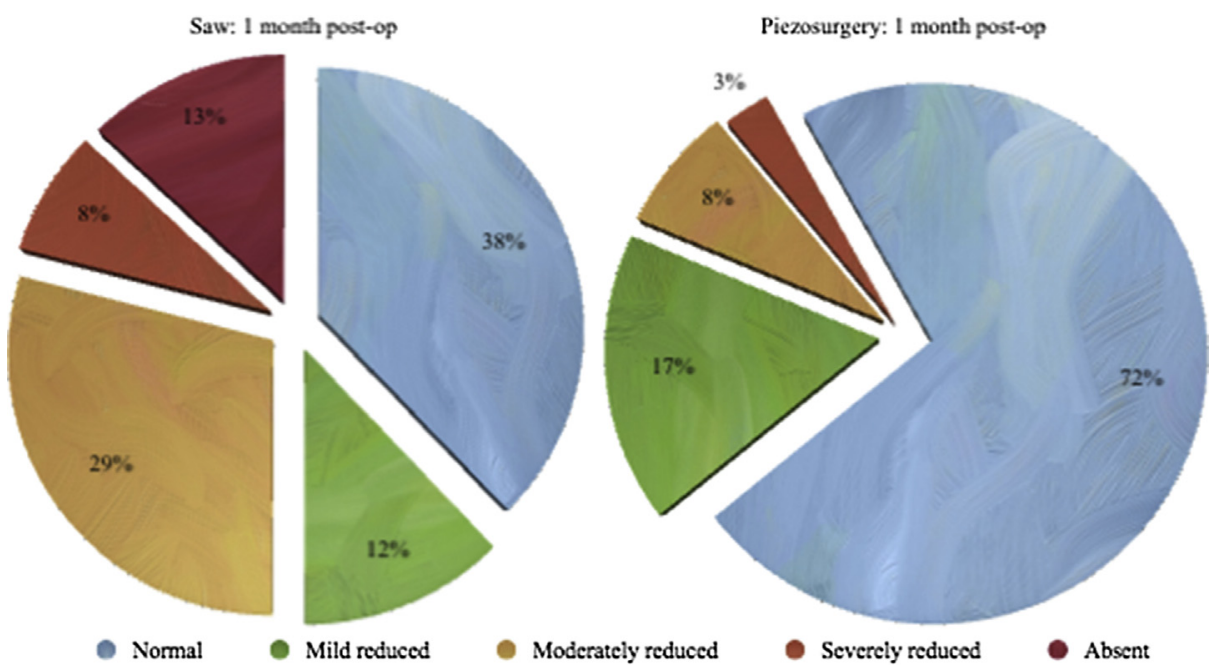

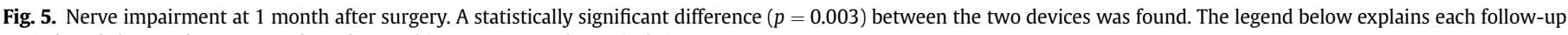
period, and the numbers reported on the graphic represent each surgical site.

anatomical sites, maxillary and mandible, in piezoelectric surgery ( $p=0.059)$, but the mandible procedure duration time was approximately 40\% longer than the maxillary procedures $(p=0.0003)$. This can allow us to confirm that even though bimaxillary surgery has been described to result in a major volume of blood loss directly related to the operative time and magnitude of the intervention (Pineiro-Aguillar et al., 2011), piezoosteotomy ensures a more controlled bleeding process than traditional devices.

It must be stressed anyway, that piezoelectric and conventional osteotomy demand different manual controls by the surgeon; in fact, whereas incision could be accelerated by exerting more pressure on a rotary bur, excessive pressure on an ultrasonic tip could prevent its vibration and lead to decreased cutting precision and consequently to a higher risk for bleeding and poor osteotomy outcome quality, although there is a trade-off with the risk of thermal bone damage (Blus and Szmukler-Moncler, 2006). In fact, the operator should have a good tactile awareness of the saw cutting and entering the bone, in order to minimise accidental damage of the surrounding tissue (Khambay and Walmsley, 2000a, 2000b: Nusrath and Postlethwaite, 2011). Some authors have regarded it as a disadvantage of ultrasonic osteotomy which required operating technique differs from conventional procedure, with longer acquisition time (Khambay and Walmsley, 2000a; Blus and Szmukler-Moncler, 2006). This justifies the need of a different learning curve in piezoelectric device, even for well traditional procedure trained surgeons. In our study the surgeon was comparably trained in both of techniques and this helped, in our study, in not influencing the measurement of surgical procedure time neither the evaluation of the other parameters.

We have been the first to try to report the incidence of postoperative swelling and haematoma in a scientific fashion and results of our clinical follow-up have demonstrated a decreased incidence of postoperative swelling $(p=0.05)$ and haematoma $(p=0.2)$ in piezoelectric sides treated.

At the same time, neurosensibility testing showed a significantly decreased incidence of nerve injury than in traditional procedures at 1 month after surgery $(p=0.003)$. In our series the nerve recovery rate was higher following both ultrasound and traditional osteotomies compared to rates published in literature for mechanical cutting, which suggest that approximately $70 \%$ of patients had recovered at nearly 1 year after surgery (Westermark et al., 1999; Gruber et al., 2005), compared with our findings of $72 \%$ and $97 \%$ of normal neurosensibility at 6 months and 1 year, respectively. Same results have been reported by Beziat et coll. (Gruber et al., 2005; Beziat et al., 2007) who described a higher percentage of sensation recovery of the inferior lip following ultrasound osteotomy. In fact, in subsequent case series (Bovi, 2005; Geha et al., 2006; Sakkas et al., 2008; Stübinger et al., 2008) ultrasonic osteotomy has been described as minimally harmful for the inferior alveolar nerve (IAN) (Landes et al., 2008a). This result could be explained by the total preservation of the soft tissues (Kohles et al., 1997; Lumley, 1997; Vercellotti et al., 2001), including microvessels surrounding the perineurium of the infraorbital and alveolar nerves by piezoelectric device vibrations, avoiding stretching and warming of the nerve. This is in agreement with many other reports of ultrasound osteotomy (Khambay and Walmsley, 2000a, 2000b; Siervo et al., 2004) This mechanism could explain the faster recovery and wound healing following piezoelectric surgery.

Moreover, we reported in terms of "surgeon's comfort", a higher accuracy in cutting precision shown by piezoelectric device; in fact, it has been reported that surgical accuracy is facilitated by good visibility in the surgical field (Torrella et al., 1998; Gruber et al., 2005; González-García et al., 2007; Happe, 2007) guaranteed by both decreased bleeding and the evacuation of detritus by the cavitation effect. In addition, piezoosteotomy causes less splintering at the margin of the incision (Schaller et al., 2005; Hoigne et al., 2006) and allows curved cuts that are impossible with rotary or oscillating saws (Hoigne et al., 2006); these advantages should allow the design of osteotomies that maintain bone contact or interdigitation after repositioning, thus minimizing the need for osteofixation (Landes et al., 2008a), and may be of interest in bone surgeries where a particular geometric design of the osteotomy is required.

Finally, ultrasonic bone cutting has allowed the realization of new surgical procedures in fact several published experimental studies have examined the consequences of ultrasound for subsequent bone regeneration. Vercellotti et al. (Vercellotti et al., 2005) reported that in periodontal resection experiments on dogs, bone had increased 8 weeks after ostectomy/osteoplasty with ultrasound, but had decreased if carbide or diamond burs had been used. Preti et al. as well, (Preti et al., 2007) found that bone around titanium implants set in minipig tibias exhibited fewer inflammatory cells, lower proinflammatory cytokine levels, and more active neoosteogenesis 7 weeks after surgery if the bone had 
a

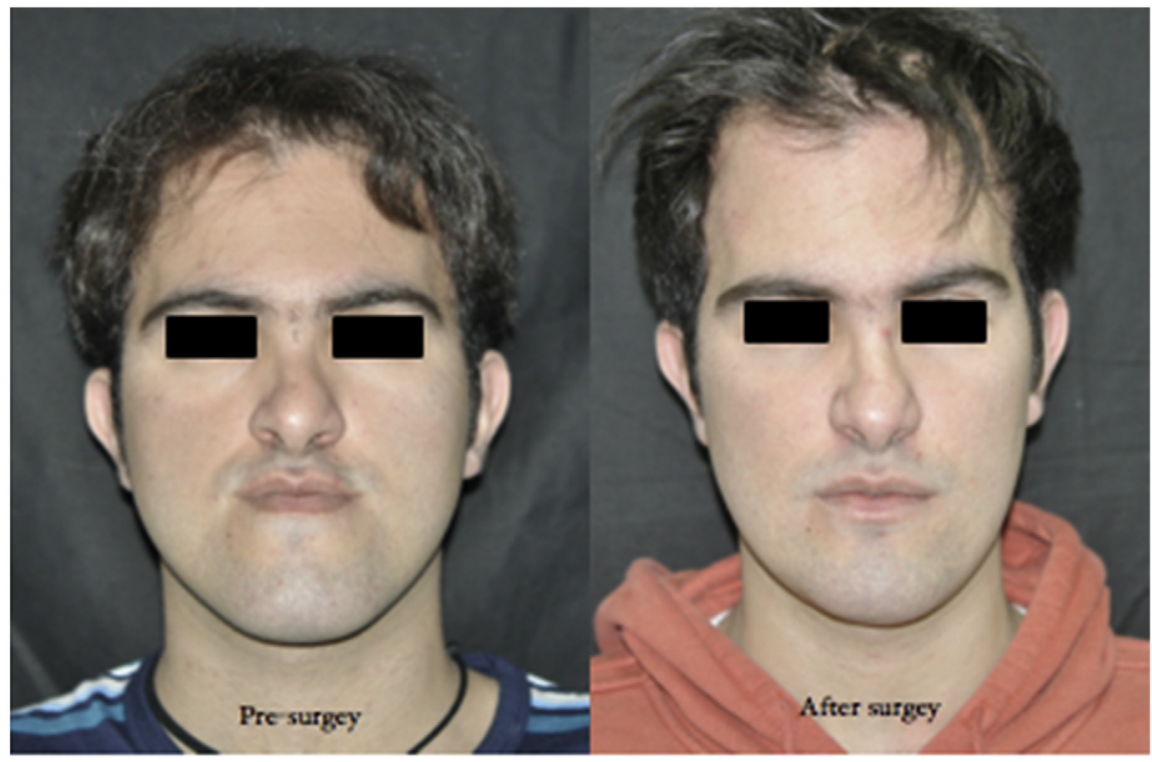

b

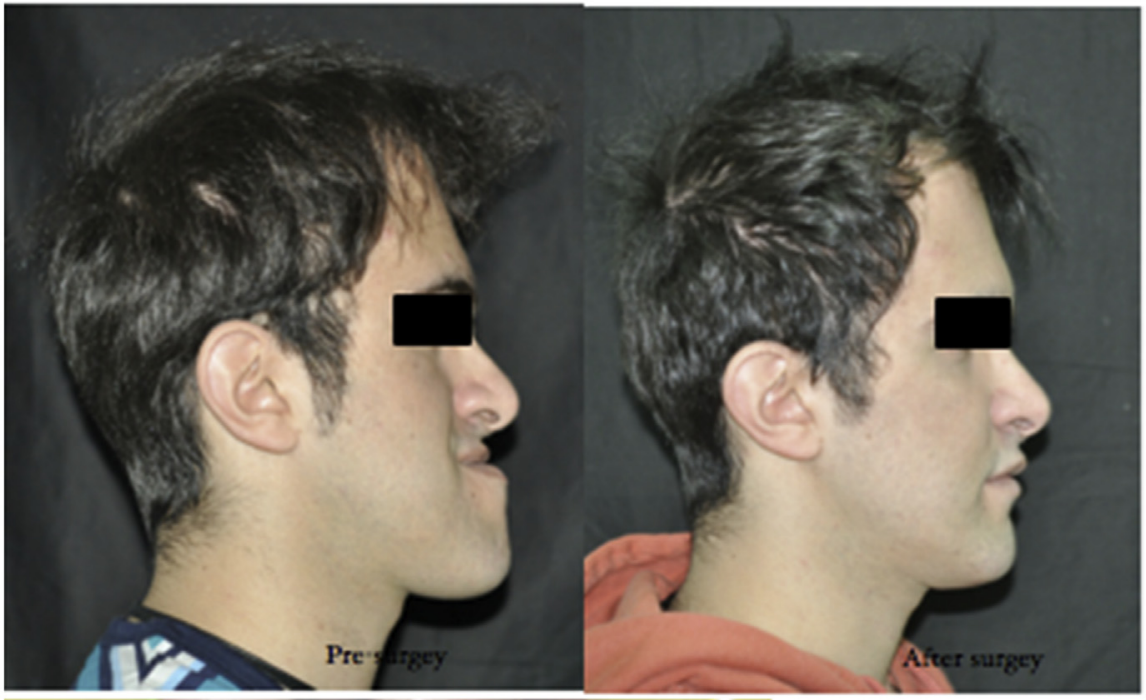

C
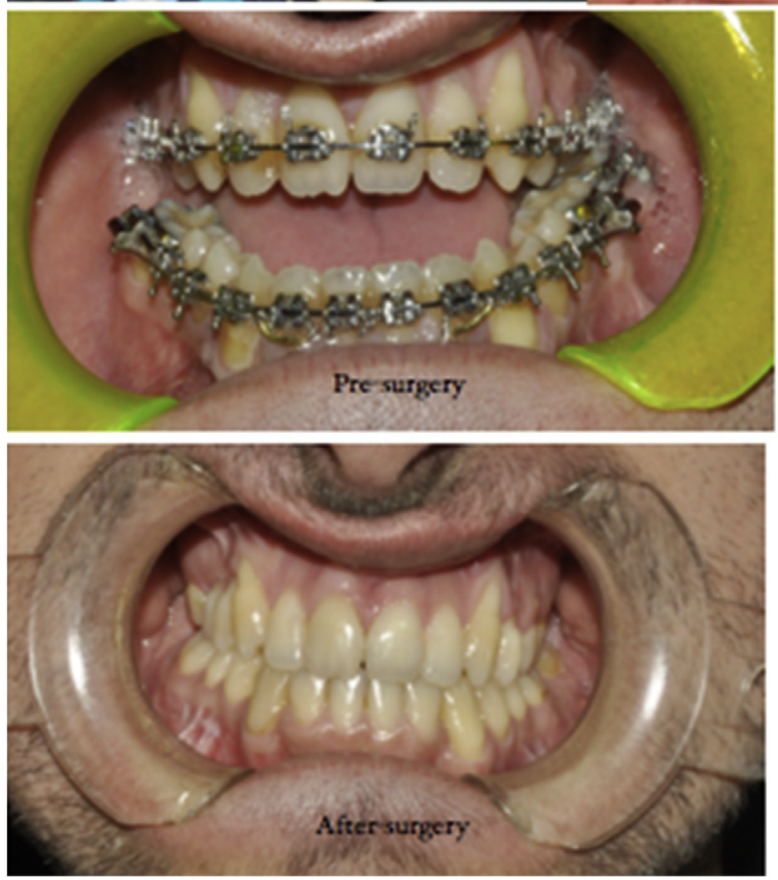

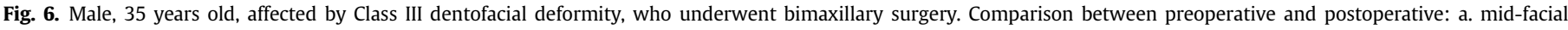
deformity improvement (frontal view), b. mid-facial deformity improvement (right side) and c. occlusal relationship. 
been prepared by ultrasonic osteotomy than if conventional drilling had been used. In the end, although experimental in vitro and in vivo studies have mainly suggested that bone regeneration after ultrasonic osteotomy is no worse than after conventional osteotomy, experiences using it in alveolar distraction osteogenesis have been disappointing as reported above. At present, we are working on a preliminary study on the possible use of mesenchymal stem cells in promoting wound healing following orthognathic surgery together with the use of a piezoelectric device. Our preliminary data show a slightly significant trend toward recovering within a shorter time, but further evaluation in appropriately sized studies is needed.

To conclude our discussion, we saw how controlling intraoperative bleeding to prevent excessive blood loss requires a good view of the surgical field, a good knowledge of anatomy, and the exercise of care during the intervention; thus here we used and proposed an endoscopic-assisted procedure, which has already described in literature (Gonzàlez-Garcìa, 2012) and modified based on our personal experience, that was helpful in the osteotomy of the posterior maxilla, of the medial wall of the maxillary sinus and of the inferior ridge of the jaw. This technique allowed us to achieve greater intraoperative visible control with a consequent increase in safety, especially in those anatomically difficult areas. We believe that the assistance of the endoscope could improve the control and precision of the osteotomy process itself, and allow surgeons to use a safer approach because the osteotomy is controlled during the whole process. Unfavourable fractures may occasionally occur during the classical intraoral approach due to the limited exposure of the mandibular ramus, which could be avoided by this technical support of direct visualisation of the surgical field.

\section{Conclusions}

In conclusion piezoosteotomy has advantages over traditional methods as it allows for precise cutting, and causes minimal wastage of bone with minimal damage to soft tissues. It reduces blood loss, and the effect of air cavitation gives better intraoperative visibility, postoperative healing is excellent with minimal heating of bone, and no extra time is needed for most operations although there is a learning curve of four to five cases for most procedures. Thus, we recommend the use of an ultrasonic device in cases of significant risk of damage to the nerves or other soft tissues of major importance; otherwise, where soft tissue damage is less likely to constitute a severe complication, and where the osseous postsurgical neoformation is decisive for the success of surgery, it may be more desirable for a professional with sufficient expertise to use a conventional technique. A combined sequential use of ultrasonic and conventional techniques could be more effective overall than any one approach by itself. Perhaps the main point to be aware of regarding cutting efficiency is its poor capacity to cut dense bone, and the greater the likelihood that the osteotome tip will break; and its performance regarding postoperative bone regeneration is still unclear and will require further evaluation in appropriately sized studies. This technique resulted in a very high efficiency in performing orthognathic procedures and this preliminary report justifies proposing piezoelectric device as the first choice for this surgery. Further studies are needed to affirm its possible use in other types of surgical correction for facial deformities.

\section{Financial disclosure}

None of the authors has financial conflicts or interests to report in association with the contents of this paper.

\section{Previous presentations}

International Piezosurgery Academy on the 15th of June 2013.

\section{Conflict of interest statement}

All authors disclose any financial and personal relationships with other people or organisations that could in appropriately influence their work.

\section{Acknowledgements}

This manuscript was approved by all of the authors and all of the authors participated in writing and correcting this work. Furthermore, all of the authors assure that manuscript has not been published nor is under consideration by other journals or editors and that they have no conflicts of interest, financial or otherwise.

\section{References}

Barone A, Santini S, Marconcini S, Giacomelli L, Gherlone E, Covani U: Osteotomy and membrane elevation during the maxillary sinus augmentation procedure. A comparative study: piezoelectric device vs. conventional rotative instruments. Clin Oral Implants Res 19: 511-515, 2008

Beziat JL, Bera JC, Lavandier B, Gleizal A: Ultrasonic osteotomy as a new technique in craniomaxillofacial surgery. Int J Oral Maxillofac Surg 36: 493-500, 2007

Beziat JL, Faghahati S, Ferreira S, Babic B, Gleizal A: Intermaxillary fixation: technique and benefit for piezosurgical sagittal osteotomy. Rev Stomatol Chir Maxillofac 110: 273-277, 2009

Blus C, Szmukler-Moncler S: Split-crest and immediate implant placement with ultra-sonic bone surgery: a 3-year life-table analysis with 230 treated sites. Clin Oral Implants Res 17: 700-707, 2006

Bovi M: Mobilization of the inferior alveolar nerve with simultaneous implant insertion: a new technique. Case report. Int J Periodontics Restorative Dent 25: 375-383, 2005

Eggers G, Klein J, Blank J, Hassfeld S: Piezosurgery: an ultrasound device for cutting bone and its use and limitations in maxillofacial surgery. $\mathrm{Br} J$ Oral Maxillofac Surg 42: 451-453, 2004

Geha HJ, Gleizal AM, Nimeskern NJ, Beziat JL: Sensitivity of the inferior lip and chin following mandibular bilateral sagittal split osteotomy using piezosurgery. Plast Reconstr Surg 118: 1598-1607, 2006

Gilles R, Couvereur T, Dammous S: Ultrasonic orthognathic surgery: enhancements to established osteotomies. Int J Oral Maxillofac Surg 42(8): 981-987, 2013

Gonzàlez-Garcìa R: Case report: endoscopically-assisted subcondylar and vertical ramus osteotomies for the treatment of symmetrical mandibular prognathism. JOMS 40: 393-395, 2012

González-García A, Diniz-Freitas M, Somoza-Martín M, García-García A: Piezoelectric bone surgery applied in alveolar distraction osteogenesis: a technical note. Int J Oral Maxillofac Implants 22: 1012-1016, 2007

Gonzalez-Garcia A, Diniz-Freitas M, Somoza-Martin M, Garcia-Garcia A: Ultrasonic osteotomy in oral surgery and implantology. Oral Surg Oral Med Oral Pathol Oral Radiol Endod 108: 306-367, 2009

Grenga V, Bovi M: Piezoelectric surgery for exposure of pala - tally impacted canines. J Clin Orthod 38: 446-448, 2004

Gruber RM, Kramer FJ, Merten HA, Schliephake H: Ultrasonic surgery an alternative way in orthognathic surgery of the mandible. A pilot study. Int J Oral Maxillofac Surg 34: 590-593, 2005

Happe A: Use of a piezoelectric surgical device to harvest bone grafts from the mandibular ramus: report of 40 cases. Int J Periodontics Restorative Dent 27: 241-249, 2007

Hoffmann E, Rader C, Fuhrmann H, Maurer P: Styloid-carotid artery syndrome treated surgically with piezosurgery: a case report and literature review. J Craniomaxillofac Surg 41: 162-166, 2013

Hoigne DJ, Stübinger S, Von Kaenel O, Shamdasani S, Hasenboehler P: Piezoelectric osteotomy in hand surgery: first experiences with a new technique. BMC Musculoskelet Disord 7(36), 2006

Kahnberg KE: Correction of maxillofacial asymmetry using orthognathic surgical methods. J Craniomaxillofac Surg 25: 266-269, 1997

Khambay BS, Walmsley AD: Investigations into the use of an ultrasonic chisel to cut bone. Part 2: cutting ability. J Dent 28: 39-44, 2000a

Khambay BS, Walmsley AD: Investigations into the use of an ultrasonic chisel to cut bone. Part 1: forces applied by clinicians. J Dent 28: 31-37, 2000b

Kohles SS, Bowers JR, Vailas AC, Vanderby Jr R: Ultrasonic wave velocity measurement in small polymeric and cor- tical bone specimens. J Biomech Eng 119: 232-236, 1997

Kotrikova B, Wirtz R, Krempien R, Blank J, Eggers G, Samiotis A, et al: Piezosurgery a new safe technique in cranial osteoplasty? Int J Oral Maxillofac Surg 35: 461-465, 2006 
Kramer FJ, Baethge C, Swennen G, Telzrow T, Schulze A, Berten J, et al: Intra- and perioperative complications of the LeFort I osteotomy: a prospective evaluation of 1000 patients. J Craniofac Surg 15: 971-977, 2004

Kramer FJ, Ludwig HC, Materna T, Gruber R, Merten HA, Schliephake H: Piezoelectric osteotomies in craniofacial procedures: a series of 15 pediatric patients. Technical note. J Neurosurg 104: 68-71, 2006

Landes CA, Stübinger S, Rieger J, Williger B, Ha TK, Sader B: Critical evaluation of piezoelectric osteotomy in orthognathic surgery: operative technique, blood loss, time requirement, nerve and vessel integrity. J Oral Maxillofac Surg 66: 657-674, 2008a

Landes CA, Stübinger S, Ballon A, Sader R: Piezoosteotomy in orthognathic surgery versus conventional saw and chisel osteotomy. J Oral Maxillofac Surg 12: 139-147, 2008b

Leclercq P, Zenati C, Dohan DM: Ultrasonic bone cut part 2: state-of-the-art specific clinical applications. J Oral Maxillofac Surg 66: 183-188, 2008

Lee SJ, Park KH: Ultrasonic energy in endoscopic surgery. Yonsei Med J 40: 545-549, 1999

Lumley PJ: Cutting ability of heliosonic, rispisonic, and shaper files. J Endod 23: 221-224, 1997

Lynn JG, Zwemer RL, Chick AJ: The biological application of focused ultrasonic waves. Science 96: 119-120, 1942

Maurer P, Kriwalsky MS, Block Veras R, Vogel J, Syrowatka F, Heiss C: Micromorphometrical analysis of conventional osteotomy techniques and ultrasonic osteotomy at the rabbit skull. Clin Oral Implants Res 19: 570-575, 2008

Nada RM, Sugar AW, Wijdeveld MG, Borstlap WA, Clauser L, Hoffmeister B, KuijpersJagtman AM: Eurocran distraction osteogenesis group: current practice of distraction osteogenesis for craniofacial anomalies in Europe: a web based survey. J Craniomaxillofac Surg 38: 83-89, 2010

Nusrath MA, Postlethwaite KR: Use of piezosurgery in calvarial bone grafts and for release of the inferior alveolar nerve in sagittal split osteotomy: technical note. Br J Oral Maxillofac Surg 49: 668-669, 2011

Peñarrocha M, Martí E, García B, Gay C: Relationship of periapical lesion radiologic size, apical resection, and retrograde filling with the prognosis of periapical surgery. J Oral Maxillofac Surg 65: 1526-1529, 2007

Pineiro-Aguillar A, Somoza-Martin M, Gandara-Rey JM, Garcia-Garcia A: Blood loss in orthognathic surgery: a systematic review. JOMS 69: 885-892, 2011

Preti G, Martinasso G, Peirone B, Navone R, Manzella C, Muzio G, et al: Cytokines and growth factors involved in the osseointegration of oral titanium implants positioned using piezoelectric bone surgery versus a drill technique: a pilot study in minipigs. J Periodontol 78: 716-722, 2007

Sakkas N, Otten JE, Gutwald R, Schmelzeisen R: Transposition of the mental nerve by piezosurgery followed by postoperative neurosensory control: a case report. Br J Oral Maxillofac Surg 46: 270-271, 2008
Schaller BJ, Gruber R, Merten HA, Kruschat T, Schliephake H, Buchfelder M, et al Piezoelectric bone surgery: a revolutionary technique for minimally invasive surgery in cranial base and spinal surgery? Technical note. Neurosurgery 57(4), 2005

Schlee M, Steigmann M, Bratu E, Garg AK: Piezosurgery: basics and possibilities. Implant Dent 15: 334-340, 2006

Shelley ED, Shelley WB: Piezosurgery: a conservative approach to encapsulated skin lesions. Cutis 38: 123-126, 1986

Siervo S, Ruggli-Milic S, Radici M, Siervo P, Jager K: Piezoelectric surgery. An alternative method of minimally invasive surgery. Schweiz Monatssch Zahnmed 114: 365-377, 2004

Sohn DS, Ahn MR, Lee WH, Yeo DS, Lim SY: Piezoelectric osteotomy for intraora harvesting of bone blocks. Int J Periodontics Restorative Dent 27: 127-131, 2007

Stübinger S, Kuttenberger J, Filippi A, Sader R, Zeilhofer HF: Intraoral piezosurgery: preliminary results of a new technique. J Oral Maxillofac Surg 63: 1283-1287, 2005

Stübinger S, Landes C, Seitz O, Zeilhofer HF, Sader R: Ultrasonic bone cutting in oral surgery: a review of 60 cases. Ultraschall Med 29: 66-71, 2008 [German]

Telzrow T, Kramer FJ, Schulze A, Baethge C, Brachvogel P: Perioperative complications following sagittal split osteotomy of the mandible. J Craniomaxillofac Surg 33: $307-313,2005$

Torrella F, Pitarch J, Cabanes G, Anitua E: Ultrasonic ostectomy for the surgical approach of the maxillary sinus: a technical note. Int J Oral Maxillofac Implants 13: $697-700,1998$

Vercellotti T, Pollack AS: A new bone surgery device: sinus grafting and periodontal surgery. Compend Contin Educ Dent 27: 319-325, 2006

Vercellotti T, de Paoli S, Nevins M: The piezoelectric bony window osteotomy and sinus membrane elevation: introduction of a new technique for simplification of the sinus augmentation procedure. Int J Periodontics Restorative Dent 21: $561-567,2001$

Vercellotti T, Nevins ML, Kim DM, Nevins M, Wada K, Schenk RK, et al: Osseous response following resective therapy with piezosurgery. Int J Periodontics Restorative Dent 25: 543-549, 2005

Westermark A, Englesson L, Bongenhielm U: Neurosensory function after sagittal split osteotomy of the mandible: a comparison between subjective evaluation and objective assessment. Int J Adult Orthodon Orthognath Surg 14: 268-274 1999

Yu CN, Chow TK, Kwan AS, Wong SL, Fung SC: Intra-operative blood loss and operating time in orthognathic surgery using induced hypotensive genera anaesthesia: prospective study. Hong Kong Med J 6: 307, 2000 